\title{
Two-Stage Super-Efficiency Slacks-Based Model to Assess China's Ecological Wellbeing
}

\author{
Jundong Hou *(-), Xinxin Ruan, Jun Lv and Haixiang Guo \\ School of Economics \& Management, China University of Geosciences, Wuhan 430074, China; \\ ruanxinxin@yeah.net (X.R.); lvjun@cug.edu.cn (J.L.); faterdumk0732@sina.com (H.G.) \\ * Correspondence: houjundong@cug.edu.cn; Tel.: +86-189-8613-8760
}

Received: 5 September 2020; Accepted: 24 September 2020; Published: 26 September 2020

\begin{abstract}
As industrialization and urbanization in China have significantly increased ecological problems such as environmental pollution and resource waste, it has become important to be able to comprehensively assess ecological wellbeing performance (EWP) when seeking high-quality human wellbeing and economic growth within specific ecological limits. Therefore, to explore the EWP spatial and temporal distribution characteristics, this paper established an evaluation index system that considers ecological economic efficiency and economic welfare efficiency from input and output perspectives. The EWPs in 30 Chinese provinces (autonomous regions, municipalities) from 2006 to 2017 were then measured using a two-stage super-efficiency slacks-based model (Super-SBM) and data envelopment analysis (DEA) window analysis method. It was found that: (1) the average EWP value in the Chinese provinces was relatively low at 0.698, with the highest EWP in Beijing, Hainan, and Shanghai and the lowest in Xinjiang, Ningxia, and Qinghai; (2) the average provincial EWP fluctuated from 2006 to 2017 with a "decline-rise-decline-rise" feature; (3) China's EWP value was spatially supported by the quadrangular "Beijing-Shanghai-Hainan-Sichuan" pole and continued to radiate to areas along these lines. These research findings provide theoretical insights and practical implications for regional ecological protection and human welfare improvements in China.
\end{abstract}

Keywords: ecological wellbeing performance; super-efficiency SBM model; DEA window analysis method

\section{Introduction}

Economic globalization and regional economic integration have led to significant increases in China's urbanization levels from $17.92 \%$ in 1978 to $60.60 \%$ in 2019 [1]. While this rapid and continuous urbanization has resulted in economic prosperity and social progress [2], it has also resulted in serious environmental problems such as ecological deterioration, environmental pollution, and excessive resource consumption. According to preliminary calculation, in 2019, China's total energy consumption reached an equivalent of 4.86 billion tons of standard coal, an increase of 3.3\% over the previous year [1]. This has not only brought severe challenges to most Chinese provinces [2,3], but has also pushed China's industrial development to the limits of its resource and environmental carrying capacities [4]. In 2019, China's carbon dioxide emissions is 9825.8 million tonnes through consumption of oil, gas and coal for combustion related activities, and the growth rate per annum is $3.4 \%$, which accounts for $28.8 \%$ of the world's share [5]. The forecast urbanization and primary energy consumption growth trends for 2050 [6] indicate that these significant ecological pollution and resource depletion pressures are going to continue to be a problem in China [7].

The aim of provincial development is to benefit the residents and ensure a comfortable and satisfactory living environment [8]. However, current industrial and urbanization pressures are far greater than the surrounding ecosystems can bear and economic gains far beyond any increases in 
human wellbeing [9]. Therefore, to address these environmental and wellbeing issues, ecological consumption efficiency and human wellbeing levels must be attained within ecological thresholds [8]. To realize win-win coordinated economic growth and ecological and human wellbeing aims, it is vital to assess the ecological wellbeing performance (EWP) growth. The EWP was initially proposed by Daly [10] to assess the efficiencies associated with converting natural resources and ecological inputs into human wellbeing [2]. The EWP is essentially a quantitative indicator that reflects the relative changes and degree of harmony between human wellbeing improvements and ecological resource consumption. Consequently, accurately evaluating EWP to properly protect the environment has become a key focus for governments and economic environmental researchers.

Along these lines, this paper evaluated the EWPs in 30 Chinese provinces. Specifically, the main objectives were: (1) to establish an index system to accurately measure the EWP; (2) to design a reasonable model to assess the EWP in 30 Chinese provinces from 2006 to 2017; and (3) to determine the temporal and spatial gaps between the different provinces to enable sustainable policy implementation.

The remainder of this paper is organized as follows. Section 2 reviews related works and the associated limitations and outlines the contributions of this paper; Section 3 details the model specification, variables, and data sources; Section 4 presents the analysis results; and Section 5 concludes the study and gives some potential research directions.

\section{Literature Review}

"Sustainable development" came into use in policy circles in 1987 and was the first overview of the globe considering the environmental features of development from an economic, social, and political comprehensive perspective [11]. Subsequently, this term attracted significant attention in an academic context or that of economics, planning, business, or environmental policy after the first Earth Summit in Rio de Janeiro in 1992 [12]. However, it is argued that the definition of sustainable development was either morally repugnant or logically redundant [13]. Theoretically, ecological economics states that large scale economic growth is restricted by the limits of the environment [10]. Based on this supposition, Daly [10] argued that national sustainability could be evaluated using the ratio of improved human wellbeing to the ecological resources consumed to improve this wellbeing, from which the EWP idea originated. However, as no specific quantitative evaluation indicators or measurement methods were developed, it was not until Rees [14] suggested the ecological footprint per capita as a denominator that the possibility of an EWP measure attracted serious research interest from diverse disciplines such as economics and sociology. This early research was mainly focused on the evaluation approach, indicator design, and the comparison of the EWPs at national, regional, or individual city levels.

There have been two main EWP evaluation methods. The first is a single index ratio method that has generally used ecological footprint resource consumption as the denominator and human wellbeing as the numerator. However, human wellbeing numerator choices have varied: a sustainable wellbeing index [15], years of happiness [16], the human development index (HDI) [17], happy life span [18], happy life index [19], and life expectancy [20], etc. The second EWP evaluation method was a comprehensive index developed using either linear or non-linear approaches, such as regression analysis models, Data Envelopment Analysis (DEA) models [21], and Stochastic Frontier Production models. Table 1 provides a summary of these previous EWP works. 
Table 1. Related ecological wellbeing performance (EWP) studies and the varying scales.

\begin{tabular}{|c|c|c|c|c|}
\hline Scale & Authors & Method & Objective Area & Time Period \\
\hline \multirow{8}{*}{ National level } & Common (2007) [18] & $\begin{array}{l}\text { The ratio of happiness adjusted } \\
\text { life expectancy for the average } \\
\text { individual to per capita energy } \\
\text { consumption }\end{array}$ & 75 nations & 1995-2005 \\
\hline & Moran et al. (2008) [22] & $\begin{array}{l}\text { The ratio of human development } \\
\text { index (HDI) to the ecological } \\
\text { footprint }\end{array}$ & 93 countries & 1975-2003 \\
\hline & Dietz et al. (2009) [23] & $\begin{array}{l}\text { A Stochastic Frontier Production } \\
\text { model }\end{array}$ & 135 countries & 1999 \\
\hline & Knight and Rosa (2011) [24] & $\begin{array}{l}\text { Regress the average life } \\
\text { satisfaction and the ecological } \\
\text { footprint per capita }\end{array}$ & 105 countries & 2005 \\
\hline & Dietz et al. (2012) [20] & $\begin{array}{l}\text { The ratio of environmental stress } \\
\text { to wellbeing }\end{array}$ & 58 nations & 1961-2003 \\
\hline & Jorgenson et al. (2014) [25] & $\begin{array}{l}\text { The adjusted ratio of per capita } \\
\text { energy consumption to average } \\
\text { life expectancy }\end{array}$ & 12 European countries & 1992-2010 \\
\hline & Zhu et al. (2015) [26] & $\begin{array}{l}\text { The ratio of HDI to ecological } \\
\text { footprint }\end{array}$ & G20 countries & 1995-2008 \\
\hline & Zhang et al. (2018) [27] & $\begin{array}{l}\text { The ratio of HDI to per capita } \\
\text { normalized ecological footprint }\end{array}$ & 82 countries & 2012 \\
\hline \multirow{5}{*}{ Regional level } & Feng and Yuan (2016) [28] & $\begin{array}{l}\text { The ratio of HDI to normalized } \\
\text { per capita ecological footprint }\end{array}$ & 30 provinces in China & 2005-2010 \\
\hline & Xu et al. (2017) [29] & $\begin{array}{c}\text { Exploratory Spatial Data Analysis } \\
\text { method }\end{array}$ & 30 provinces in China & 2005-2014 \\
\hline & Xiao and Zhang (2019) [30] & $\begin{array}{c}\text { Improved Stochastic Frontier } \\
\text { Analysis model }\end{array}$ & 30 provinces of China & 2004-2015 \\
\hline & Fang and Xiao (2019) [31] & Super-DEA & 30 provinces of China & 2005-2016 \\
\hline & Feng et al. (2019) [9] & $\begin{array}{c}\text { The ratio of HDI to Ecological } \\
\text { Footprint }\end{array}$ & 30 provinces of China & 1994-2014 \\
\hline \multirow{5}{*}{ Individual cities } & He and Chen (2011) [32] & $\begin{array}{l}\text { The ratio of HDI to per capita } \\
\text { ecological footprint index }\end{array}$ & Shannxi province & 1990-2009 \\
\hline & Long and Wang (2017) [33] & $\begin{array}{l}\text { Super-slack-based measure } \\
\quad \text { (Super-SBM) }\end{array}$ & Shanghai city & 2006-2014 \\
\hline & Long (2019) [34] & $\begin{array}{l}\text { Super-efficiency network SBM } \\
\text { model }\end{array}$ & 35 major cities in China & 2011-2015 \\
\hline & Bian, Ren \& Liu (2020) [8] & Super-SBM & $\begin{array}{l}30 \text { provincial capital } \\
\text { cities in China }\end{array}$ & 2011-2016 \\
\hline & Bian et al. (2020) [2] & Super-SBM & 278 Chinese cities & 2005-2016 \\
\hline
\end{tabular}

As shown in Table 1, most of these previous studies involved EWP comparisons at national, provincial, or individual city scales using two evaluation methods. Although these studies have significantly contributed to EWP research, there are still some gaps. (1) While there are broadly accepted scale, efficiency, and equity definitions, there has not been any broad consensus on an EWP evaluation index [23]. Therefore, accurate EWP measurements remain to be explored. (2) Existing evaluations have tended to employ proportion analysis methods; however, as countries, provinces, and cities are complex ecological systems with various inputs and outputs, depending solely on proportions cannot fully represent the variations in the ecological resource or human wellbeing levels [8]. Therefore, more recently, Super slack-based measure model (SBM) or stochastic frontier approaches (SFA) have been used to concurrently assess the various input and output efficiencies [2]; however, these methods make it difficult to explain how the key resource and environmental indicators can be improved [34].

Therefore, because of these gaps in previous EWP research, this study makes three main contributions. First, along with the traditional resource consumption ecological input, some related capital indicators are introduced to reflect the ecological capital investment efficiency and more comprehensively compute the provincial level EWP. Second, as EWP growth can be decomposed into the multiplication of two items: economic performance (EP) from the consumption of natural resources up to the ecological threshold and wellbeing performance (WP) from economic growth up to the welfare threshold [9], a super-efficiency network SBM model and DEA window analysis method were combined to examine the ecological input "black box" transformation into a wellbeing output in 30 Chinese provinces. Third, the overall EWP trend and spatial-temporal distribution characteristics were 
analyzed, the results from which could provide governments with important guidance on promoting better regional EWP in China.

\section{Methodology}

\subsection{Selection of Input-Output Indicators}

Designing a set of appropriate indicators is the first step to evaluating the EWP. According to the definition of EWP, social benefits and ecological cost can be employed to measure this concept. Nevertheless, the Ecoeconomics theory argues that there are two barriers in green development-one is ecological threshold, which indicates that economic growth is dependent on the supply capacity of natural system resources, and another is welfare threshold, which represents whether economic growth can cause the continuous improvement of social welfare [9]. Based on this proposition, Daly [35] suggested that the EWP could be represented as the economic efficiency of natural expenditure (EP) multiplied by the wellbeing performance of economic growth (WP), as shown in Formula (1).

$$
\begin{aligned}
E W P & =\frac{W B}{E F}=\frac{G D P}{E F} \times \frac{W B}{G D P} \\
& =E P \times W P
\end{aligned}
$$

where GDP, $E F$, and $W B$, respectively, represent the economic growth, the ecological footprint, and wellbeing gained. This indicates that the EWP can be divided into two stages (Figure 1): a first stage, focused on the efficiency of transforming the ecological input into economic output (i.e., ecological economy efficiency), and a second stage, focused on the efficiency of converting economic input into wellbeing output (i.e., economic welfare efficiency).

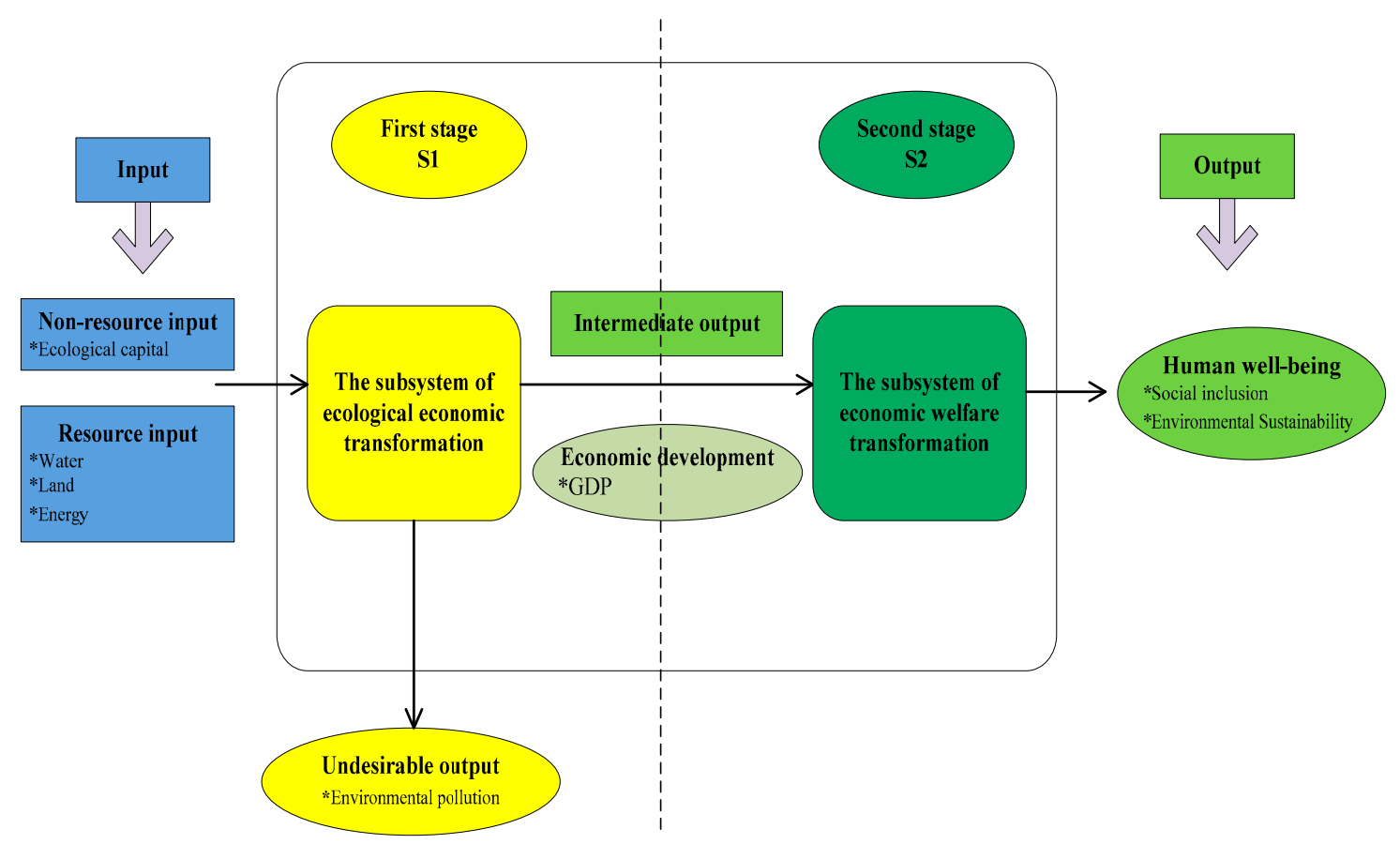

Figure 1. EWP input and output dimensions.

\subsubsection{Input Indicators}

Essentially, the purpose of the EWP is to obtain maximum welfare output under the least ecological input constraint [36]. As previous studies have indicated that resource consumption was a key ecological input indicator, this paper also selected water, land, and energy consumption as the proxy indicators for ecosystem resource consumption, which were, respectively, indicated by the per capita water consumption, the per capita built-up areas, and the per capita energy consumption. 
Ecological capital indicators, such as ecological resource capital, ecological environmental capital, and ecological service capital, have also been employed as input indicators [37]. Ecological resource capital is the ecological capital existing in tangible (such as forests, minerals, etc.) and intangible (such as light, heat, water, air, etc.) production resources; because of data availability, this was measured as the ratio of forestry investment to regional GDP. Ecological environmental capital is the environmental ecological capital such as fresh air, clean water, and climate. As the related investment methods are mainly focused on the "three wastes" treatment, ecological environment capital was determined by the ratio of the total environmental pollution treatment investment to GDP. Ecological service capital is related to the construction of urban environmental infrastructure and was measured as the ratio of urban environmental infrastructure construction investment to regional GDP.

\subsubsection{Output Indicators}

The EWP output indicators included both desirable and undesirable outputs. The undesirable output was the environmental pollution indicator and as environmental pollutants included waste water, exhaust emissions, and waste residues [8], these "three wastes" were selected to represent the environmental pollution indicators. However, unlike previous studies, a composite index was applied to measure these three wastes, as shown in Table 2.

Table 2. Main characteristics for the EWP input-output indicators.

\begin{tabular}{|c|c|c|c|}
\hline Category & 1st Tier Indicators & 2nd Tier Indicators & 3rd Tier Indicators \\
\hline \multirow{6}{*}{ Input Indicators } & \multirow{3}{*}{ Ecological capital } & $\begin{array}{l}\text { Ecological service } \\
\text { capital }\end{array}$ & $\begin{array}{l}\text { Ratio of investment in urban environmental } \\
\text { infrastructure construction to regional GDP }\end{array}$ \\
\hline & & $\begin{array}{l}\text { Ecological } \\
\text { environment capital }\end{array}$ & $\begin{array}{l}\text { Ratio of total investment in environmental } \\
\text { pollution control to GDP }\end{array}$ \\
\hline & & $\begin{array}{l}\text { Ecological resource } \\
\text { capital }\end{array}$ & $\begin{array}{l}\text { Ratio of forestry investment completed in } \\
\text { the current year to regional GDP }\end{array}$ \\
\hline & \multirow{3}{*}{$\begin{array}{l}\text { Consumption of } \\
\text { ecological resources }\end{array}$} & Energy consumption & $\begin{array}{l}\text { Per capita energy consumption (tonnes of } \\
\text { standard coal/person) }\end{array}$ \\
\hline & & $\begin{array}{l}\text { Land resource } \\
\text { consumption }\end{array}$ & Per capita builtup area $\left(\mathrm{km}^{2} / 10,000\right.$ people $)$ \\
\hline & & $\begin{array}{l}\text { Water resource } \\
\text { consumption }\end{array}$ & Per capita water consumption $\left(\mathrm{m}^{3} /\right.$ person $)$ \\
\hline \multirow{6}{*}{ Undesirable output } & \multirow{6}{*}{ Environmental pollution } & \multirow{2}{*}{$\begin{array}{l}\text { Wastewater } \\
\text { discharge }\end{array}$} & $\begin{array}{l}\text { Per capita chemical oxygen demand } \\
\text { (tonnes/person) }\end{array}$ \\
\hline & & & $\begin{array}{l}\text { Per capita ammonia nitrogen emissions } \\
\text { (tonnes/person) }\end{array}$ \\
\hline & & \multirow{2}{*}{$\begin{array}{l}\text { Exhaust gas } \\
\text { discharge }\end{array}$} & $\begin{array}{l}\text { Per capita sulfur dioxide emissions } \\
\text { (tonnes/person) }\end{array}$ \\
\hline & & & $\begin{array}{c}\text { Per capita smoke (powder) dust emission } \\
\text { (tonnes/person) }\end{array}$ \\
\hline & & \multirow[b]{2}{*}{ Solid waste discharge } & $\begin{array}{l}\text { Per capita production of industrial solid } \\
\text { waste (tonnes/person) }\end{array}$ \\
\hline & & & $\begin{array}{c}\text { Per capita amount of municipal solid waste } \\
\text { (tonnes/person) }\end{array}$ \\
\hline \multirow{5}{*}{ Desirable Output } & Economic development & $\begin{array}{l}\text { Technological } \\
\text { innovation }\end{array}$ & R\&D input as a proportion of GDP \\
\hline & \multirow{4}{*}{ Social welfare } & Social Inclusion & $\begin{array}{l}\text { Urban registered unemployment rate at the } \\
\text { end of the year }\end{array}$ \\
\hline & & \multirow{3}{*}{$\begin{array}{l}\text { Environmental } \\
\text { Sustainability }\end{array}$} & Average education (years) \\
\hline & & & $\begin{array}{l}\text { Number of health technicians per } 1000 \\
\text { population }\end{array}$ \\
\hline & & & Forest coverage \\
\hline
\end{tabular}


As in previous papers, the core desirable output indicator was GDP [38]. However, as it has been argued that GDP oriented output indicators should be frequently varied, the United Nations Development Program (UNDP) universal human development index (HDI) was chosen. Generally, the HDI measures wellbeing from three specific health, education, and income dimensions [9]. Therefore, based on the sustainable development goals (SDGs) for 2030, the "average education years", "number of health technicians per 1000 population", and "urban registered unemployment rate at the end of the year" were taken as the education, medical treatment, and employment levels to comprehensively assess social inclusiveness. The environmental welfare desirable output measure was the forest resource coverage rate. Unlike the traditional GDP economic measurement index, the proportion of R\&D investment in GDP was selected as the intermediate rather than a final output index to measure the provincial economic development levels.

Because the Chinese provincial level data does not include the average education years in each province, Equation (2) was used to compute this based on the [30].

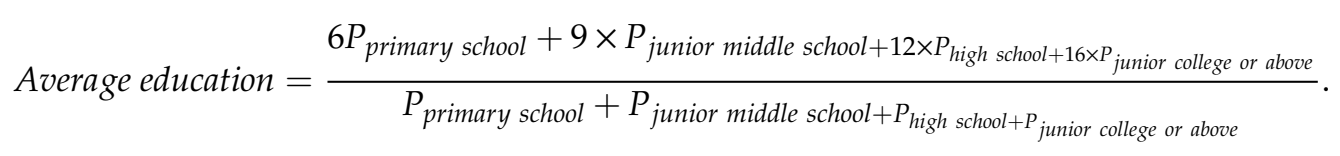

where $P_{i}$ is the number of students at each education stage.

\subsection{Assessment Model}

The DEA input-output model first proposed by Charnes et al. [39] has been widely used for efficiency evaluations, including the EWP, for which the indicators included economic development, social welfare, resource consumption, environmental pollution, and others [40]. However, traditional DEA measurements based on radial features have been found to have inaccuracies as they ignore the slack variables [41], fail to take the undesirable outputs into consideration, and can overstate the efficiencies [42]. To overcome these limitations, Tone [43] proposed a slack-based measure model (SBM) that was able to obtain the slack degrees for each input-output indicator in a single-stage DEA efficiency evaluation. However, both the traditional DEA and the improved SBM saw the production processes as a "black box" for single-stage EWP efficiency assessments, which was somewhat unrealistic [34]. Therefore, Tone and Tsutsui [44] extended and proposed a network DEA model within the slacks-based measure framework that was non-radial and was able to individually deal with the inputs/outputs to obtain non-uniform input/output factor efficiencies. Therefore, to comprehensively consider the two stages shown in Figure 1, the super-efficiency DEA model and the SBM model were combined into a super efficiency network SBM model (Super-SBM) with non-radial considerations and undesirable outputs to evaluate the EWP, the development of which is given in the following steps.

(1) Assuming that there are $n$ provinces (or decision-making units, DMUs) for the analysis (in this case, $n=30$ ), with each province having $m$ input indicators $(x)$ to produce $v_{1}$ desirable outputs $\left(y^{g}\right)$ and $v_{2}$ undesirable outputs $\left(y^{b}\right)$. We deonte $x_{i j}$ as a measure of the $i$ th input of $\mathrm{DMU}_{\mathrm{j}}$ and $y_{r j}$ as the measure of the $r$ th output of $\mathrm{DMU}_{\mathrm{j}}$, where $x_{i j}>0, y_{i j}>0$.

(2) Since the orientation of input or output will impact the slack of input or output, in order to ensure the reasonability of computing results, the non-oriented model is applied. Under the condition of variable return to scale, the EWP computation is established as follows:

$$
\rho_{s e}^{*}=\min \frac{\sum_{k=1}^{K} \omega^{k}\left[1+\frac{1}{m_{k}}\left(\sum_{i=1}^{m_{i}} \frac{s_{i}^{k^{-}}}{x_{i 0}^{k}}\right)\right]}{\sum_{k=1}^{K} \omega^{k}\left[1-\frac{1}{v_{1 k}+v_{2 k}}\left(\sum_{r=1}^{v_{1 k}} \frac{s_{r}^{g k}}{y_{r 0}^{g k}}+\sum_{r=1}^{v_{2 k}} \frac{s_{r}^{b k}}{y_{r 0}^{k k}}\right)\right]} .
$$


In Formula (3), $\rho_{s e}^{*}$ is the efficiency value of EWP and $\omega$ is the weight. When $\rho_{s e}^{*}<1$, it indicates that the DMU is inefficient and when $\rho_{s e}^{*}>1$, the DMU is in an active state.

$$
\text { s.t. }\left\{\begin{array}{c}
\sum_{j=1, \neq 0}^{n} x_{i j}^{k} \lambda_{j}^{k}+s_{i}^{k^{-}}=\theta^{k} x_{i 0^{\prime}}^{k}, i=1, \ldots, m_{k}, k=1, \ldots, K \\
\sum_{j=1, \neq 0}^{n} x_{r j}^{k} \lambda_{j}^{k}+s_{r}^{g k}=\varphi^{k} y_{r 0}^{g k}, r=1, \ldots, s_{r}, k=1, \ldots, K \\
\sum_{j=1, \neq 0}^{n} x_{r j}^{k} \lambda_{j}^{k}+s_{r}^{b k}=\delta^{k} y_{r 0}^{b k}, r=1, \ldots, s_{r}, k=1, \ldots, K \\
\varepsilon \leq 1-\frac{1}{v_{1 k}+v_{2 k}}\left(\sum_{r=1}^{v_{1 k}} \frac{s_{r}^{g k}}{y_{r 0}^{g k}}+\sum_{r=1}^{v_{2 k}} \frac{s_{r}^{b k}}{y_{r 0}^{b k}}\right) \\
z^{(k, h)} \lambda^{h}=z^{(k, h)} \lambda^{k}, \sum_{j=1, \neq 0}^{N} \lambda_{j}^{k}=\sum_{k=1}^{K} \omega^{k}=1 \\
\lambda_{k} \geq 0, s^{k-} \geq 0, s^{g k} \geq 0, s^{b k} \geq 0, \omega^{k} \geq 0
\end{array} .\right.
$$

Formula (4) is the constraint. Where $k$ is the number of stages; $m_{k}, v_{k}, \varphi_{k}$ are the number of inputs, outputs, and intermediate indicators in the $k$ stage; $(h, k)$ denotes the connection from stage $k$ to stage $h$; $x, y$, and $z$ are the input, output, and intermediate output; $\lambda_{k}$ is the weight of stage $k$; and $s^{k-}, s^{g k}, s^{b k}$ are the slack variables of the input, desirable output, and undesirable output, respectively.

Here, $k=2$ as there are two stages in this study. As the ecological economy efficiency and welfare transformation efficiency are of equal importance in the EWP evaluation, $\lambda_{1}=\lambda_{2}=0.5$ [34].

(3) DEA Window Analysis. If the time is ignored or the performance of some DMU is compared to a period of time, this can result in an excessive use of resources and production deficiencies in future periods [45]. To overcome these issues, the DEA window analysis described in Charnes et al. [46] can be used to determine the EWP and observe the efficiency shifts over time. The core concept of DEA window analysis suggests that the DMU in each period is a different DMU, which means that different reference sets are selected to evaluate the relative efficiency of the DMU using the moving average method [45]. The moving average method not only increases the number of DMUs, but also allows for the easy comparison of the DMU performance with the DMU performance in other time periods (i.e., longitudinal dimension) or with other DMUs in the same time period (i.e., horizontal dimension), which allows for a comprehensive analysis of the change tendencies in each DMU's efficiency and a comparison of the differences between the DMUs.

To monitor the flexibility and accuracy of the measurement, a window length needs to be set. Although there is no current theory for defining window length, previous studies have suggested a window of 3-5 years [45]; therefore, as the EWP for the 30 Chinese provinces was assessed over a 12-year period, a 3-year window was selected.

\subsection{Data Collection}

This paper assessed the EWP of Chinese provinces rather than cities for several reasons. First, most data available is at the provincial level. Second, China's sustainable development goals are focused on provinces, each of which varies in political status and cultural and socio-economic development. Third, the assessment of the provincial EWP provides specific guidance for industrial restructuring and sustainable development [9]. Based on data availability, continuity, and comparability, production decision-making units were selected from 30 Chinese provinces, not including Tibet, Taiwan, Hong Kong, or Macau. Because the Chinese central government proposed to construct a resource-economic, environmentally friendly society that emphasized a harmonious coexistence between man and nature to achieve sustainable development in 2007 and most types of statistics yearbooks failed to be updated to 2019, relevant data from 2006 to 2017 were collected.

The corresponding indicator data shown in Table 2 were acquired from public sources: the annual China Environmental Statistical Yearbooks (2007-2018), China Statistical Yearbooks, China Land and Resources Yearbooks (2007-2018), China Energy Statistical Yearbooks (2007-2018), and China Educational Statistical Yearbooks (2007-2018). Missing data for some certain years or some variables were accounted for using mean substitution and regression imputation. Variables affected by price 
changes were normalized to 2005 to eliminate the inflation impact and due to the different measurement units, logarithmic methods were adopted to preprocess data such as per capita GDP.

\section{Empirical Analysis}

\subsection{Overall EWP Analysis}

\subsubsection{Comprehensive EWP Level}

MaxDEA (Version 6.16, Beijing Realworld Software Company Ltd., Beijing, China) software that is most powerful DEA software and supports negative variables and supports the SBM super efficiency model containing the undesirable outputs was used to calculate the EWPs of the 30 Chinese provinces from 2006 to 2017 based on the Super-NSBM model and the DEA window analysis, the results from which are shown in Table 3. Based on the annual average value in each province under the different windows in each year, the 30 provinces were ranked. The overall EWP for the 30 Chinese provinces was 0.698 , which was far from SBM-efficient. 
Table 3. The EWPs of 30 provinces during 2006-2017.

\begin{tabular}{|c|c|c|c|c|c|c|c|c|c|c|c|c|c|c|c|}
\hline Region & Provinces & 2006 & 2007 & 2008 & 2009 & 2010 & 2011 & 2012 & 2013 & 2014 & 2015 & 2016 & 2017 & Average & Rank \\
\hline \multirow{10}{*}{ East region } & Beijing & 1.006 & 1.232 & 1.096 & 1.034 & 2.519 & 1.084 & 0.965 & 1.077 & 1.012 & 1.097 & 1.141 & 1.190 & 1.204 & 1 \\
\hline & Tianjin & 0.925 & 0.894 & 0.826 & 0.857 & 1.110 & 0.934 & 1.120 & 1.086 & 0.988 & 0.989 & 1.237 & 1.051 & 1.002 & 4 \\
\hline & Hebei & 0.379 & 0.408 & 0.465 & 0.471 & 0.492 & 0.544 & 0.694 & 0.840 & 0.708 & 0.720 & 0.585 & 0.834 & 0.595 & 20 \\
\hline & Shanghai & 1.004 & 1.038 & 1.106 & 1.518 & 1.051 & 0.986 & 0.694 & 1.135 & 1.022 & 0.997 & 1.108 & 1.274 & 1.078 & 3 \\
\hline & Jiangsu & 0.285 & 0.358 & 0.365 & 0.409 & 0.409 & 0.376 & 0.420 & 0.463 & 0.406 & 0.421 & 0.443 & 0.422 & 0.398 & 25 \\
\hline & Zhejiang & 1.511 & 1.026 & 1.023 & 1.008 & 1.020 & 0.745 & 0.734 & 0.785 & 0.713 & 0.690 & 0.726 & 0.827 & 0.901 & 10 \\
\hline & Fujian & 0.772 & 1.013 & 1.054 & 1.177 & 0.977 & 0.486 & 0.526 & 0.566 & 0.582 & 0.577 & 0.736 & 0.684 & 0.763 & 15 \\
\hline & Shandong & 0.358 & 0.682 & 0.670 & 0.740 & 0.741 & 0.446 & 0.443 & 0.514 & 0.487 & 0.488 & 0.555 & 0.632 & 0.563 & 21 \\
\hline & Guangdong & 0.906 & 0.901 & 0.907 & 0.921 & 0.921 & 0.918 & 0.895 & 0.923 & 0.900 & 0.909 & 0.919 & 0.922 & 0.912 & 8 \\
\hline & Hainan & 1.306 & 2.237 & 1.246 & 1.071 & 1.297 & 0.853 & 0.894 & 1.081 & 1.150 & 1.039 & 1.095 & 1.003 & 1.189 & 2 \\
\hline \multirow{6}{*}{$\begin{array}{l}\text { Central } \\
\text { region }\end{array}$} & Shanxi & 0.743 & 0.709 & 0.716 & 0.809 & 0.713 & 0.518 & 0.620 & 0.795 & 0.789 & 0.802 & 0.718 & 0.811 & 0.729 & 17 \\
\hline & Anhui & 0.837 & 0.813 & 0.809 & 0.826 & 0.807 & 0.622 & 0.718 & 0.802 & 0.783 & 0.725 & 0.826 & 0.819 & 0.782 & 14 \\
\hline & Jiangxi & 0.949 & 0.929 & 0.935 & 0.865 & 0.862 & 0.698 & 0.831 & 1.022 & 1.026 & 0.969 & 0.968 & 0.970 & 0.919 & 7 \\
\hline & Hubei & 0.722 & 0.906 & 0.722 & 0.658 & 0.695 & 0.569 & 0.587 & 0.680 & 0.587 & 0.606 & 0.511 & 0.590 & 0.653 & 18 \\
\hline & Hunan & 1.012 & 1.018 & 0.691 & 0.661 & 0.897 & 0.744 & 0.800 & 0.913 & 0.965 & 0.807 & 0.986 & 0.981 & 0.873 & 11 \\
\hline & Henan & 0.743 & 0.724 & 0.722 & 0.784 & 0.770 & 0.651 & 0.705 & 0.781 & 0.792 & 0.790 & 0.792 & 0.792 & 0.754 & 16 \\
\hline \multirow{11}{*}{ West region } & Sichuan & 0.869 & 0.869 & 0.985 & 0.982 & 0.901 & 0.790 & 0.921 & 0.919 & 0.772 & 0.943 & 0.919 & 0.959 & 0.902 & 9 \\
\hline & Chongqing & 0.511 & 0.788 & 0.479 & 0.463 & 0.411 & 0.438 & 0.555 & 0.712 & 0.698 & 0.712 & 0.938 & 0.932 & 0.637 & 19 \\
\hline & Yunnan & 0.958 & 0.956 & 0.959 & 1.044 & 1.108 & 0.809 & 0.904 & 1.104 & 1.039 & 1.010 & 0.970 & 0.963 & 0.985 & 5 \\
\hline & Guizhou & 0.805 & 0.793 & 0.812 & 0.841 & 0.834 & 0.776 & 0.798 & 0.909 & 0.948 & 0.995 & 0.985 & 0.678 & 0.848 & 13 \\
\hline & Shaanxi & 0.894 & 0.956 & 0.905 & 0.965 & 1.024 & 0.674 & 0.775 & 0.745 & 0.736 & 0.699 & 0.918 & 1.018 & 0.859 & 12 \\
\hline & Gansu & 0.281 & 0.266 & 0.296 & 0.334 & 0.296 & 0.312 & 0.293 & 0.307 & 0.318 & 0.305 & 0.336 & 0.384 & 0.311 & 26 \\
\hline & Ningxia & 0.120 & 0.138 & 0.146 & 0.236 & 0.184 & 0.215 & 0.202 & 0.197 & 0.212 & 0.199 & 0.213 & 0.241 & 0.192 & 29 \\
\hline & Qinghai & 0.197 & 0.175 & 0.171 & 0.220 & 0.199 & 0.188 & 0.208 & 0.203 & 0.230 & 0.203 & 0.203 & 0.229 & 0.202 & 28 \\
\hline & Xinjiang & 0.180 & 0.168 & 0.136 & 0.140 & 0.140 & 0.113 & 0.102 & 0.110 & 0.109 & 0.108 & 0.110 & 0.104 & 0.126 & 30 \\
\hline & Guangxi & 1.023 & 0.928 & 0.931 & 0.970 & 0.793 & 0.874 & 0.943 & 1.023 & 0.927 & 0.683 & 1.012 & 0.974 & 0.923 & 6 \\
\hline & Inner Mongolia & 0.201 & 0.235 & 0.238 & 0.243 & 0.247 & 0.200 & 0.210 & 0.237 & 0.241 & 0.235 & 0.272 & 0.271 & 0.236 & 27 \\
\hline \multirow{3}{*}{$\begin{array}{l}\text { Northeast } \\
\text { region }\end{array}$} & Liaoning & 0.415 & 0.427 & 0.410 & 0.384 & 0.428 & 0.324 & 0.329 & 0.449 & 0.499 & 0.521 & 0.634 & 0.657 & 0.456 & 23 \\
\hline & Jilin & 0.476 & 0.511 & 0.462 & 0.418 & 0.366 & 0.393 & 0.467 & 0.543 & 0.526 & 0.512 & 0.993 & 0.869 & 0.545 & 22 \\
\hline & Heilongjiang & 0.421 & 0.458 & 0.371 & 0.341 & 0.367 & 0.331 & 0.307 & 0.346 & 0.432 & 0.449 & 0.490 & 0.638 & 0.412 & 24 \\
\hline \multicolumn{2}{|c|}{ China } & 0.694 & 0.752 & 0.688 & 0.713 & 0.753 & 0.587 & 0.622 & 0.709 & 0.687 & 0.673 & 0.745 & 0.757 & 0.698 & \\
\hline \multicolumn{2}{|c|}{ East region } & 0.845 & 0.979 & 0.876 & 0.921 & 1.054 & 0.737 & 0.739 & 0.847 & 0.797 & 0.793 & 0.855 & 0.884 & 0.861 & \\
\hline \multicolumn{2}{|c|}{ Central region } & 0.834 & 0.850 & 0.766 & 0.767 & 0.791 & 0.634 & 0.710 & 0.832 & 0.824 & 0.783 & 0.800 & 0.827 & 0.785 & \\
\hline \multicolumn{2}{|c|}{ West region } & 0.549 & 0.570 & 0.551 & 0.585 & 0.558 & 0.490 & 0.537 & 0.588 & 0.566 & 0.554 & 0.625 & 0.614 & 0.566 & \\
\hline \multicolumn{2}{|c|}{ Northeast region } & 0.437 & 0.465 & 0.414 & 0.381 & 0.387 & 0.349 & 0.368 & 0.446 & 0.486 & 0.494 & 0.706 & 0.721 & 0.471 & \\
\hline
\end{tabular}


The top three and the bottom three EWP performers from 2006 to 2017 are shown in Figure 2. The average EWP in Beijing was the highest, followed by Hainan and Shanghai, all of which were located on the optimal EWP frontier curve. As Beijing was the capital of China and host of the 2008 Olympic Games, prior to and after the Olympic Games in 2008, some high-polluting industries were moved out of the city to Hebei province and several specific eco-environmental protection policies were enforced, which was possibly why Beijing was ranked first. Hainan, which had the second highest EWP, is an island province famous for its eco-tourism industry and therefore, has been paying attention to environmental protection. Shanghai, which had the third highest EWP, underwent industrial restructuring to focus on innovative, high-tech low polluting industries.

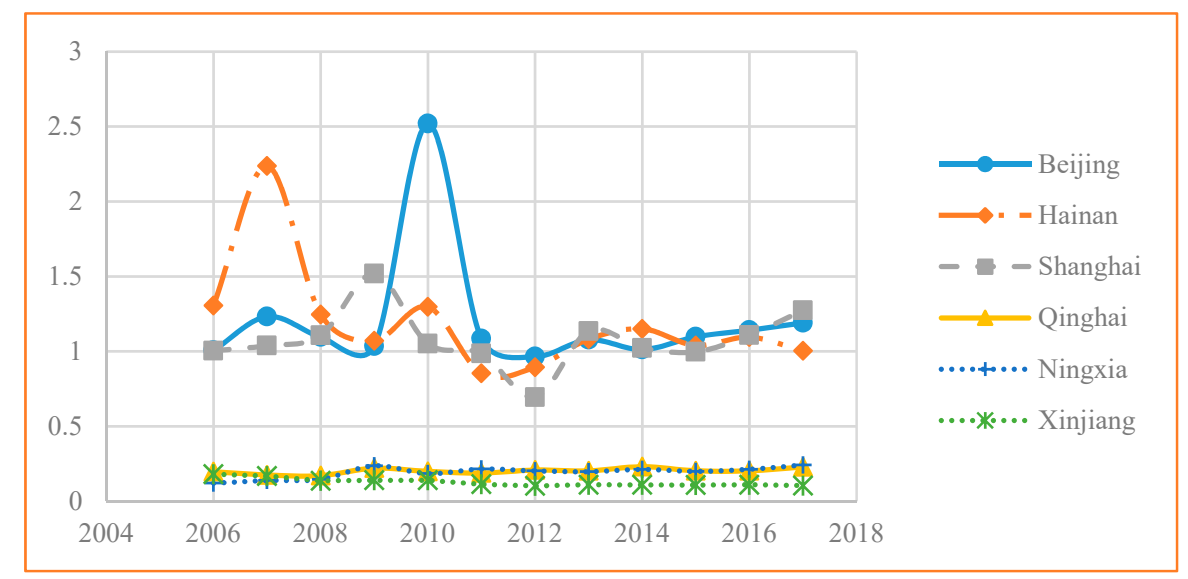

Figure 2. Top and bottom three EWP performers between 2006 and 2017.

However, Xinjiang, Ningxia, and Qinghai had the lowest EWPs (Table 3 and Figure 2) at 0.2022, 0.192, and 0.126, which was similar to the results in [8]. Xinjiang's EWP was the lowest because of its inefficient natural consumption, Ningxia had poor EWP performance because this province has many heavy chemical industries that consume excessive water resources and cause significant pollution, and Qinghai is dependent on resources and has a fragile ecosystem.

\subsubsection{Two Stage Performance}

The S1 and S2 EWP stages are shown in Table 4. The average ecological economic transformation efficiency in the 30 Chinese provinces was 0.761 and the average economic welfare transformation efficiency was 0.845 ; therefore, the S1 efficiency was slightly lower than the S2 efficiency, perhaps because the low ecological economic efficiency led to the low ecological welfare performance. The results in Table 4 indicate that over the entire surveyed period, none of 30 provinces were able to achieve DEA effectiveness concurrently in the two stages. While Beijing, Shanghai, and Tianjin had efficiencies greater than 1 in stage $S 1$, they were less than 1 in stage $S 2$, which indicated that even though these three municipalities achieved coordinated ecological environments and economic growth development, further work is needed to balance human wellbeing and economic growth development. This result was mainly because rapid urbanization and economic development resulted in excessive expansion, which depleted the per capita resources and lowered human wellbeing. However, in contrast, Guangxi, Hainan, Jilin, Inner Mongolia, and Yunnan had efficiencies less than 1 in stage S1, but higher than 1 in stage S2. Most of these provinces are located in the western region and have very fragile ecological environments and are economically backward; therefore, more work is needed to improve their ecological economic transformation performances. 
Table 4. The EWPs in stage S1 and S2 from 2006 to 2017.

\begin{tabular}{|c|c|c|c|c|c|c|c|c|c|c|c|c|c|c|c|c|c|c|c|c|c|c|c|c|c|c|c|}
\hline \multirow{2}{*}{\multicolumn{2}{|c|}{ Region }} & \multicolumn{2}{|c|}{2006} & \multicolumn{2}{|c|}{2007} & \multicolumn{2}{|c|}{2008} & \multicolumn{2}{|c|}{2009} & \multicolumn{2}{|c|}{2010} & \multicolumn{2}{|c|}{2011} & \multicolumn{2}{|c|}{2012} & \multicolumn{2}{|c|}{2013} & \multicolumn{2}{|c|}{2014} & \multicolumn{2}{|c|}{2015} & \multicolumn{2}{|c|}{2016} & \multicolumn{2}{|c|}{2017} & \multicolumn{2}{|c|}{ 2006-2017 } \\
\hline & & S1 & S2 & s1 & S2 & S1 & S2 & s1 & S2 & s1 & S2 & s1 & S2 & S1 & S2 & S1 & S2 & S1 & S2 & S1 & S2 & S1 & S2 & S1 & S2 & S1 & S2 \\
\hline \multirow{10}{*}{$\begin{array}{l}\text { East } \\
\text { region }\end{array}$} & Beijing & 1.013 & 0.959 & 1.491 & 0.233 & 1.164 & 0.788 & 1.028 & 1.010 & 4.588 & 0.395 & 1.129 & 0.816 & 1.024 & 0.883 & 1.056 & 1.043 & 1.026 & 0.960 & 1.180 & 0.773 & 1.238 & 0.671 & 1.274 & 1.016 & 1.434 & 0.796 \\
\hline & Tianjin & 1.000 & 0.861 & 1.000 & 0.809 & 1.000 & 0.706 & 0.941 & 0.804 & 1.152 & 0.867 & 0.925 & 1.010 & 1.123 & 0.997 & 1.108 & 0.956 & 1.020 & 0.922 & 1.031 & 0.890 & 1.336 & 0.591 & 1.077 & 1.001 & 1.059 & 0.868 \\
\hline & Hebei & 0.393 & 0.892 & 0.457 & 0.753 & 0.535 & 0.747 & 0.515 & 0.860 & 0.557 & 0.799 & 0.600 & 0.835 & 0.805 & 0.768 & 1.000 & 0.725 & 0.816 & 0.707 & 0.854 & 0.654 & 0.648 & 0.481 & 1.000 & 0.715 & 0.682 & 0.745 \\
\hline & Shanghai & 1.002 & 1.000 & 1.110 & 0.651 & 1.099 & 0.771 & 1.310 & 1.494 & 1.099 & 0.752 & 1.013 & 0.903 & 1.000 & 0.532 & 1.133 & 1.028 & 1.069 & 0.904 & 1.037 & 0.923 & 1.199 & 0.534 & 1.451 & 0.800 & 1.127 & 0.858 \\
\hline & Jiangsu & 0.451 & 0.328 & 0.607 & 0.340 & 0.610 & 0.327 & 0.596 & 0.355 & 0.603 & 0.329 & 0.540 & 0.302 & 0.656 & 0.359 & 0.662 & 0.429 & 0.542 & 0.467 & 0.546 & 0.492 & 0.570 & 0.371 & 0.550 & 0.540 & 0.578 & 0.387 \\
\hline & Zhejiang & 1.602 & 0.746 & 1.119 & 0.746 & 1.049 & 0.942 & 1.024 & 0.942 & 1.040 & 0.944 & 0.717 & 0.983 & 0.741 & 0.927 & 0.768 & 1.030 & 0.749 & 0.809 & 0.663 & 0.963 & 0.712 & 0.651 & 0.807 & 1.000 & 0.916 & 0.890 \\
\hline & Fujian & 0.724 & 1.000 & 1.022 & 0.990 & 1.085 & 0.934 & 1.165 & 1.099 & 0.933 & 1.163 & 0.461 & 1.000 & 0.505 & 0.983 & 0.543 & 1.000 & 0.548 & 0.984 & 0.536 & 1.002 & 0.706 & 0.667 & 0.649 & 1.000 & 0.740 & 0.985 \\
\hline & Shandong & 0.469 & 0.464 & 1.000 & 0.517 & 0.954 & 0.552 & 1.000 & 0.587 & 1.000 & 0.588 & 0.582 & 0.462 & 0.598 & 0.430 & 0.700 & 0.461 & 0.647 & 0.364 & 0.608 & 0.497 & 0.719 & 0.334 & 0.827 & 0.554 & 0.759 & 0.484 \\
\hline & Guangdong & 1.000 & 0.827 & 1.000 & 0.820 & 1.000 & 0.830 & 1.000 & 0.854 & 1.000 & 0.853 & 1.000 & 0.848 & 1.000 & 0.809 & 1.000 & 0.856 & 1.000 & 0.819 & 1.000 & 0.834 & 1.000 & 0.566 & 1.000 & 0.856 & 1.000 & 0.814 \\
\hline & Hainan & 0.669 & 4.626 & 0.964 & 3.468 & 1.231 & 1.320 & 0.983 & 1.350 & 1.297 & 1.290 & 0.757 & 1.583 & 0.848 & 1.351 & 1.030 & 1.308 & 0.674 & 3.850 & 0.845 & 1.988 & 0.717 & 2.091 & 0.915 & 1.389 & 0.911 & 2.134 \\
\hline \multirow{6}{*}{$\begin{array}{l}\text { Central } \\
\text { region }\end{array}$} & Shanxi & 1.000 & 0.591 & 1.000 & 0.549 & 1.000 & 0.558 & 1.000 & 0.679 & 0.931 & 0.570 & 0.634 & 0.779 & 0.818 & 0.676 & 1.000 & 0.660 & 1.000 & 0.651 & 1.000 & 0.670 & 0.863 & 0.456 & 1.000 & 0.682 & 0.937 & 0.627 \\
\hline & Anhui & 1.000 & 0.719 & 1.000 & 0.686 & 1.000 & 0.679 & 1.000 & 0.704 & 1.000 & 0.676 & 0.744 & 0.614 & 0.863 & 0.661 & 1.000 & 0.669 & 0.964 & 0.622 & 0.925 & 0.503 & 1.000 & 0.469 & 1.000 & 0.693 & 0.958 & 0.641 \\
\hline & Jiangxi & 1.000 & 0.903 & 1.000 & 0.867 & 1.000 & 0.878 & 0.947 & 0.763 & 0.931 & 0.816 & 0.708 & 0.944 & 0.840 & $\begin{array}{l}.001 \\
1.053\end{array}$ & 0.979 & 1.179 & 1.031 & 1.010 & 1.000 & 0.941 & 1.000 & 0.625 & 1.000 & 0.942 & 0.953 & 0.910 \\
\hline & Hubei & 0.756 & 0.683 & 1.000 & 0.829 & 0.797 & 0.728 & 0.714 & 0.761 & 0.790 & 0.602 & 0.615 & 0.623 & 0.646 & 0.641 & 0.751 & 0.695 & 0629 & 0.619 & 0.634 & & 0.560 & & 0.631 & & 0.710 & 0.679 \\
\hline & Hunan & 1.015 & 0.980 & 1.029 & 0.992 & 0.691 & 0.944 & 0.674 & 0.820 & 0.941 & 0.837 & 0.768 & 0.803 & 0.809 & 0.972 & 0.957 & 0.871 & 1.000 & 0.932 & 0.839 & 0.759 & 1.000 & 0.649 & 1.000 & 0.963 & 0.894 & 0.877 \\
\hline & Henan & 1.000 & 0.591 & 1.000 & 0.567 & 1.000 & 0.565 & 1.000 & 0.645 & 1.000 & 0.626 & 0.799 & 0.629 & 0.886 & 0.627 & 1.000 & 0.641 & 1.000 & 0.655 & 1.000 & 0.653 & 1.000 & 0.437 & 1.000 & 0.655 & 0.974 & 0.608 \\
\hline \multirow{11}{*}{$\begin{array}{l}\text { West } \\
\text { region }\end{array}$} & Sichuan & 1.000 & 0.768 & 1.000 & 0.768 & 1.066 & 0.769 & 1.029 & 0.926 & 1.000 & 0.820 & 0.879 & 0.654 & 1.000 & 0.854 & 1.000 & 0.851 & 0.838 & 0.716 & 1.000 & 0.892 & 0.974 & 0.565 & 1.000 & 0.922 & 0.982 & 0.792 \\
\hline & Chongqing & 0.622 & 0.414 & 1.000 & 0.651 & 0.631 & 0.414 & 0.542 & 0.536 & 0.466 & & 0.493 & & 0.615 & 0.740 & 0.798 & 0.780 & 0.669 & 1.001 & & 0.8 & 1.000 & & 1.000 & & 13 & 0.669 \\
\hline & Yunnan & 1.000 & 0.919 & 1.000 & 0.916 & 1.000 & 0.922 & 1.024 & 1.098 & 1.125 & 1.105 & 0.774 & 1.088 & 0.875 & 1.107 & 1.102 & 1.027 & 0.989 & 1.221 & 1.005 & 1.044 & 1.000 & 0.628 & 1.000 & 0.929 & 0.991 & 1.000 \\
\hline & Guizhou & 1.000 & 0.673 & 1.000 & 0.658 & 1.000 & 0.683 & 1.000 & 0.726 & 1.000 & 0.716 & 0.894 & 0.760 & 0.881 & 0.845 & 1.000 & 0.833 & 1.000 & 0.901 & 0.978 & 1.132 & 1.000 & 0.646 & 0.621 & 1.426 & 0.948 & 0.833 \\
\hline & Shaanxi & 1.000 & 0.808 & 1.116 & 0.552 & 1.000 & 0.826 & 1.056 & 0.751 & 1.118 & 0.665 & 0.711 & 0.632 & 0.818 & 0.801 & 0.797 & 0.644 & 0.756 & 0.729 & 0.696 & 0.737 & 0.955 & 0.533 & 1.110 & 0.626 & 0.928 & 0.692 \\
\hline & & 0.527 & 0.230 & 0.537 & 0.201 & 0.589 & 0.194 & 0.544 & 0.273 & 0.478 & 0.332 & 0.463 & 0.3 & 0.447 & 0.447 & 0.477 & 0.408 & 0.466 & 0.467 & 0.449 & 0.4 & 0.507 & & 0.580 & & 0.505 & 0.344 \\
\hline & Ningxia & 0.158 & 0.529 & 0.183 & 0.449 & 0.190 & 0.549 & 0.221 & 1.050 & 0.183 & 0.901 & 0.204 & 0.940 & 0.226 & 0.806 & 0.214 & 0.882 & 0.216 & 1.108 & 0.193 & 1.256 & 0.211 & 0.751 & 0.195 & 1.905 & 0.199 & 0.927 \\
\hline & Qinghai & 0.351 & 0.321 & 0.340 & 0.311 & 0.313 & 0.425 & 0.351 & 0.569 & 0.358 & 0.385 & 0.330 & 0.42 & 0.395 & 0.361 & 0.332 & 0.523 & 0.360 & 0.572 & 0.285 & 0.739 & 0.292 & 0.445 & 0.306 & 0.881 & 0.334 & 0.496 \\
\hline & $x$ & 0.239 & 0.975 & 0.267 & 0.694 & 0.227 & 0.632 & 0.189 & 0.929 & 0.225 & 0.639 & 0.174 & 0.7 & 0.157 & 0.743 & 0.165 & 0.778 & 0.162 & 0.788 & 0.160 & 0.782 & 0.172 & 0.495 & 0.173 & 0.555 & 0.193 & 0.728 \\
\hline & Guangxi & 0.806 & 2.080 & 1.000 & 0.866 & 1.000 & 0.871 & 1.000 & 0.942 & 0.781 & 1.002 & 0.897 & 0.895 & 0.940 & 1.017 & 0.975 & 1.224 & 0.919 & 1.053 & 0.625 & 1.349 & 0.876 & 1.083 & 1.000 & 0.950 & 0.901 & 1.111 \\
\hline & $\begin{array}{c}\text { Inner } \\
\text { Mongolia }\end{array}$ & 0.163 & 1.763 & 0.203 & 1.443 & 0.211 & 1.368 & 0.205 & 1.510 & 0.223 & 1.241 & 0.176 & 1.417 & 0.188 & 1.318 & 0.212 & 1.277 & 0.218 & 1.250 & 0.212 & 1.240 & 0.244 & 0.880 & 0.239 & 1.466 & 0.208 & 1.348 \\
\hline & Liaoni & 0.374 & 1.0 & $0.4 \mathrm{C}$ & 0.7 & 0. & 0. & 0. & 0. & 0.4 & 0. & 0.3 & 0.605 & 0. & 0. & 0.430 & 0.8 & 0.457 & 1. & 0. & 1. & 0.5 & 0.862 & 0.618 & 1.013 & 0.424 & 873 \\
\hline & 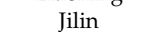 & 0.445 & 0.975 & 0.503 & 0.885 & 0.429 & 0.859 & 0.377 & 1.028 & 0.346 & 0.805 & 0.354 & 1.007 & 0.397 & 1.481 & 0.435 & 1.886 & 0.409 & 2.0 & 0.406 & 1.896 & 0.885 & 1.088 & 0.811 & 1.325 & 0.483 & 1.273 \\
\hline & Heilongiiang & 0.381 & 1.000 & 0.429 & 1.003 & 0.342 & 0.974 & 0.310 & 1.000 & 0.334 & 1.000 & 0.302 & 0.876 & 0.278 & 0.947 & 0.312 & 0.991 & 0.388 & 1.000 & 0.405 & 1.000 & 0.448 & 0.743 & 0.610 & 1.000 & 0.378 & 0.961 \\
\hline & & 0.7 & 0.9 & 0.8 & 0.8 & 0.7 & 0.7 & 0.7 & 0.8 & 0.8 & 0. & 0.6 & 0. & 0.6 & 0.8 & 07 & 0.8 & 0.719 & 0.9 & 0.7 & 0. & 0.780 & 0.652 & 0.815 & 33 & 61 & 845 \\
\hline & region & 0.832 & 1.170 & 0.977 & 0.933 & 0.973 & 0.792 & 0.956 & 0.936 & 1.327 & 0.7 & 0.772 & 0.874 & 0.830 & 0.804 & 0.900 & 0.884 & 0.809 & 1.079 & 0.830 & 0.902 & 0.885 & 0.696 & 0.955 & 0.887 & 0.921 & 0.896 \\
\hline Cen & al region & 0.962 & 0.7 & 1.005 & 0.74 & 0.915 & 0.725 & 0.8 & 0.729 & 0.932 & 0. & 0.71 & 0.732 & 0.810 & 0.772 & & 0.7 & & 0.748 & 0.900 & 0.713 & 0.904 & & 0.939 & 0.798 & 0.904 & 0.724 \\
\hline & 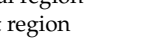 & 0.624 & 0.86 & 0.695 & 0.68 & 0.657 & 0.696 & 0.6 & 0.8 & 0.63 & 0.7 & 0.5 & 0.778 & 0.5 & 0.822 & 0.643 & 0.8 & 0.599 & 0.891 & 0.575 & 0.947 & 0.657 & 0.6 & 0.657 & 1.000 & 0.627 & 0.813 \\
\hline North & t t region & 0.400 & 0.992 & 0.446 & 0.888 & 0.392 & 0.790 & 0.353 & 0.889 & 0.365 & 0.808 & 0.323 & 0.829 & 0.333 & 1.006 & 0.392 & 1.246 & 0.418 & 1.378 & 0.408 & 1.590 & 0.632 & 0.898 & 0.680 & 1.113 & 0.428 & 1.036 \\
\hline
\end{tabular}




\subsection{EWP Temporal Analysis}

\subsubsection{Provincial Perspective}

Figure 3 shows the EWP values each year in the 30 Chinese provinces from 2006 to 2017. As can be seen, the overall EWP was not high, with the average EWP being 0.694 in 2006 and only increasing marginally to 0.757 in 2017. The EWP value fluctuated across the 12 years, but in general, was improving, with more noticeable improvements obvious from 2011, the first year of the 12th Chinese Five-year plan in which green sustainable development was first stressed. Specifically, the Chinese provinces began to focus on urbanization quality rather than speed and consequently implemented polices aimed at improving their EWP, such as the Green Development Index, the National New-Type Urbanization Plan, and environmental protection and human wellbeing policies [47].

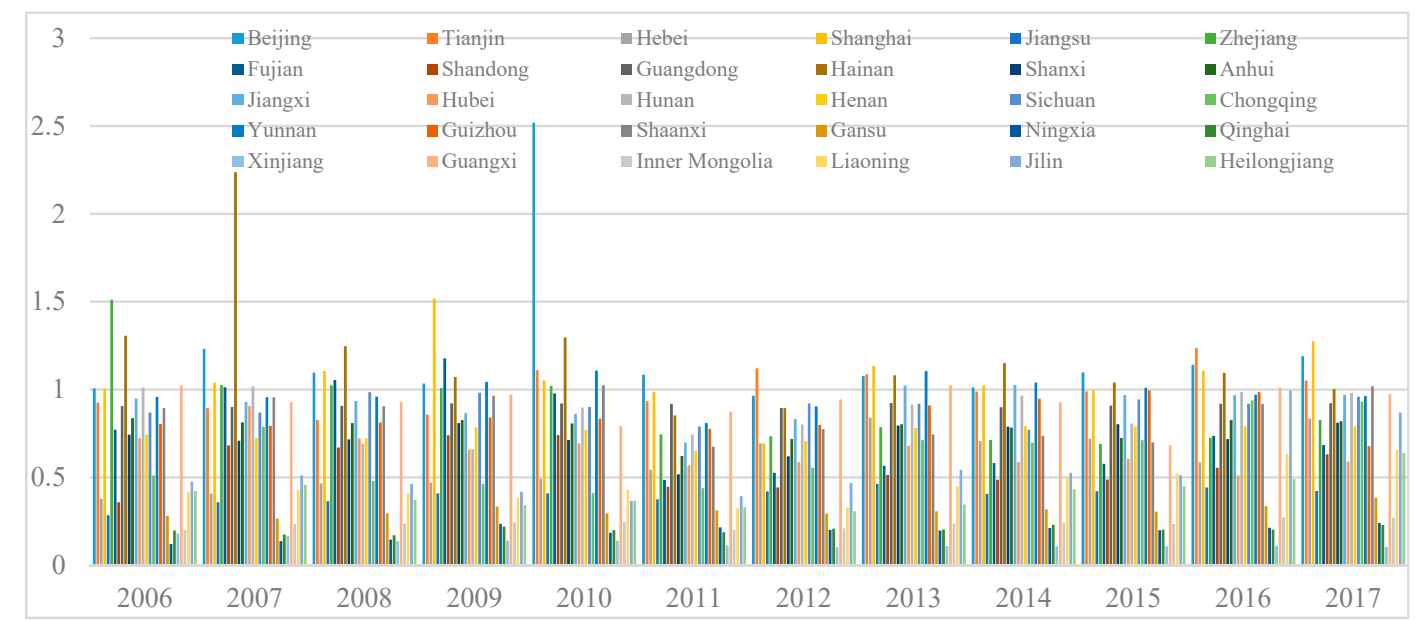

Figure 3. The EWP of the 30 Chinese provinces from 2006 to 2017.

\subsubsection{Regional perspective}

To compare the regional EWP differences over time, the 30 provinces were sorted into east, central, west, and northeast regions based on the statistical demarcations of the Chinese Statistical Bureau [48].

Figure 4 shows the average EWPs for the four major regions and the entire country from 2006 and 2017.

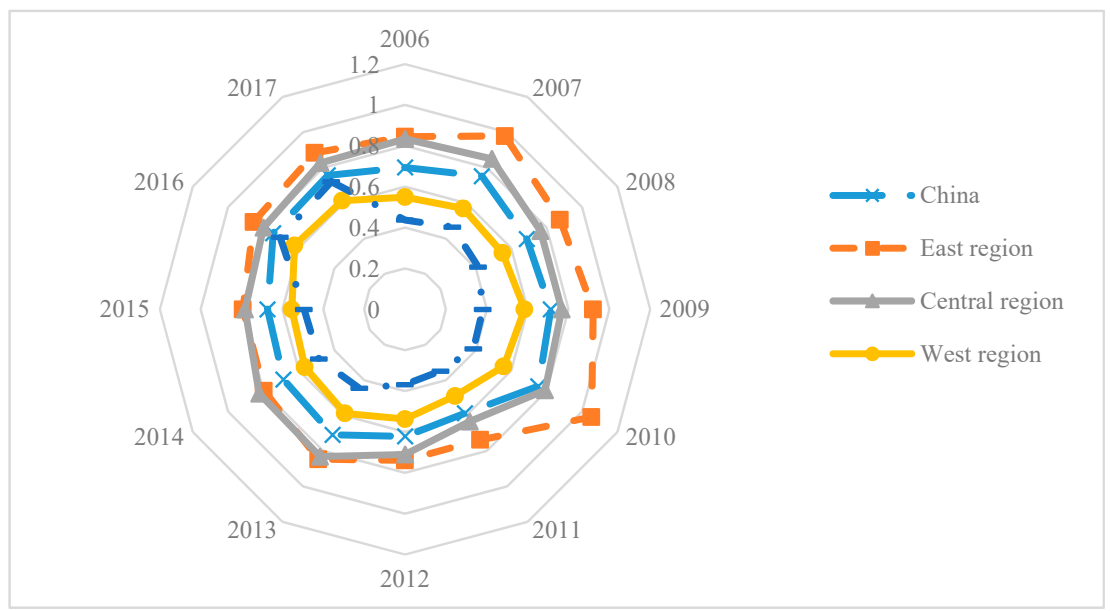

Figure 4. Average EWP values in the different Chinese regions from 2006 to 2017.

As shown in Figure 4, the EWP in all regions increased considerably from 2008 to 2010 and decreased sharply from 2010 to 2011; then, similar to provincial trends, there was a noticeably 
synchronous improvement in the average EWP from 2011, with the gap between the eastern and the central regions gradually narrowing. Therefore, the temporal EWP distribution trends in the different provinces and in the regions experienced a "decline-rise-decline-rise" variation trend over the period.

\subsection{EWP Spatial Analysis}

\subsubsection{EWP Spatial pattern}

The average EWP values in the 30 Chinese provinces in the east, central, northeast, and western regions were, respectively, $0.861,0.785,0.471$, and 0.566 , which indicated that there were obvious regional differences between 2006 and 2017 (Figure 4).

As shown in Figure 4, the east and central regions had the highest average EWPs, well above the overall Chinese EWP. The eastern region has natural geographical advantages, preferential policies, and good employment opportunities, which in turn, give rise to positive cumulative economy, education, health, and medical care effects. Further, because of the industrial upgrading in this region, many of the high energy consuming, high polluting industries have been gradually moving to other regions. Although the central region is an important manufacturing agglomeration area and the main region for the high energy consuming, high polluting industrial transfers, the government has implemented several policies, such as the construction of a two-oriented society and the green development of the Yangtze River Economic Belt, to facilitate green industrial clusters. However, in the west and northeast regions, the average EWPs were below the national average, with the northeast region's being lower than in the west.

Overall, the Chinese provincial EWP pattern was the highest in the eastern region, followed by the central region, the western region, and the northeast region. To some extent, these results reflect the differences in the regional ecological capital, resource consumption, environmental pollution, and residential welfare input-output efficiencies.

To further analyze the EWP between the different provinces, ArcGIS 10.5 software was used to visualize the EWP distributions in the 30 provinces in 2006, 2011, and 2017, as shown in Figures 5-7.

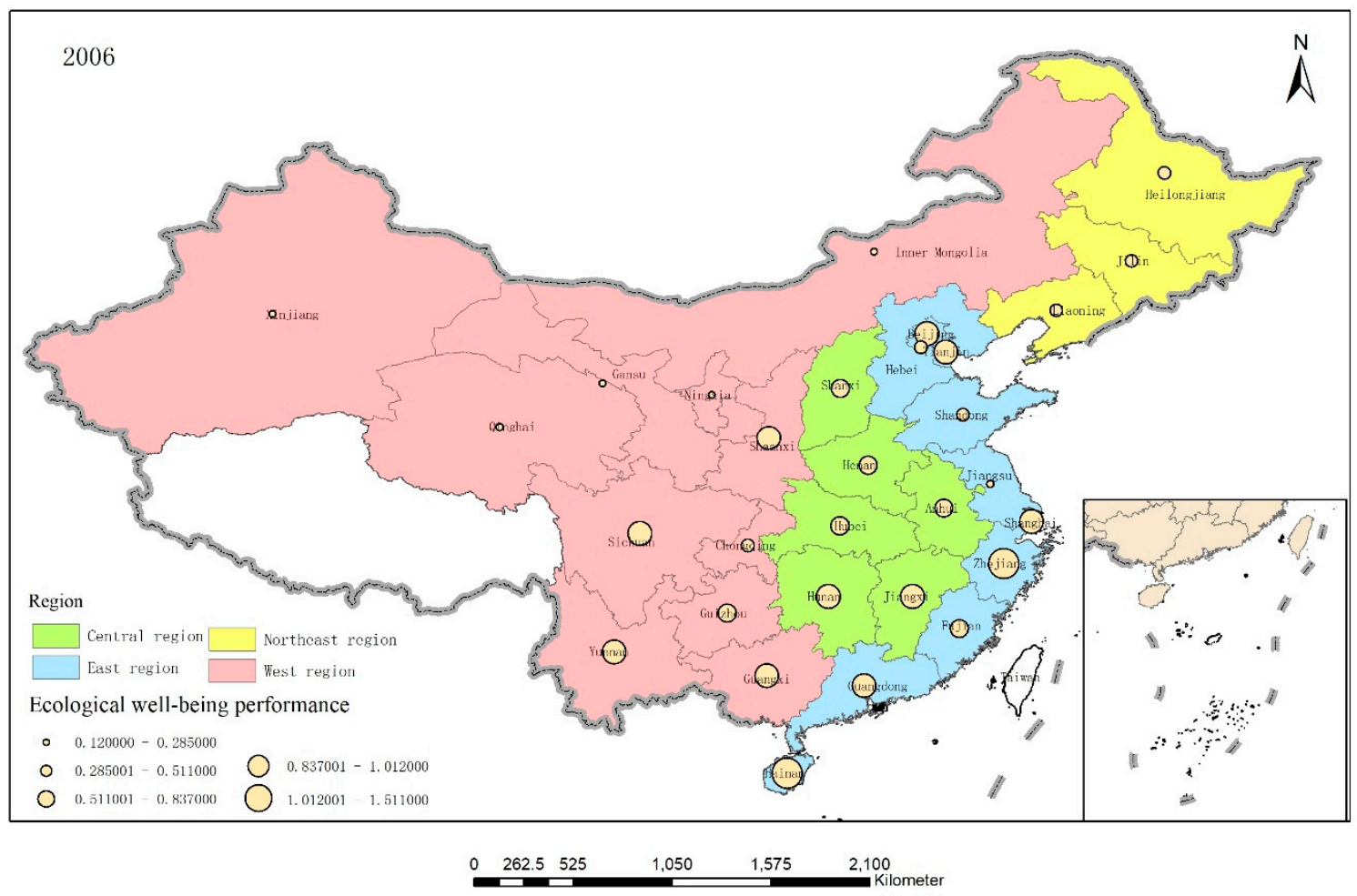

Figure 5. The EWP distributions in the 30 provinces in 2006. 


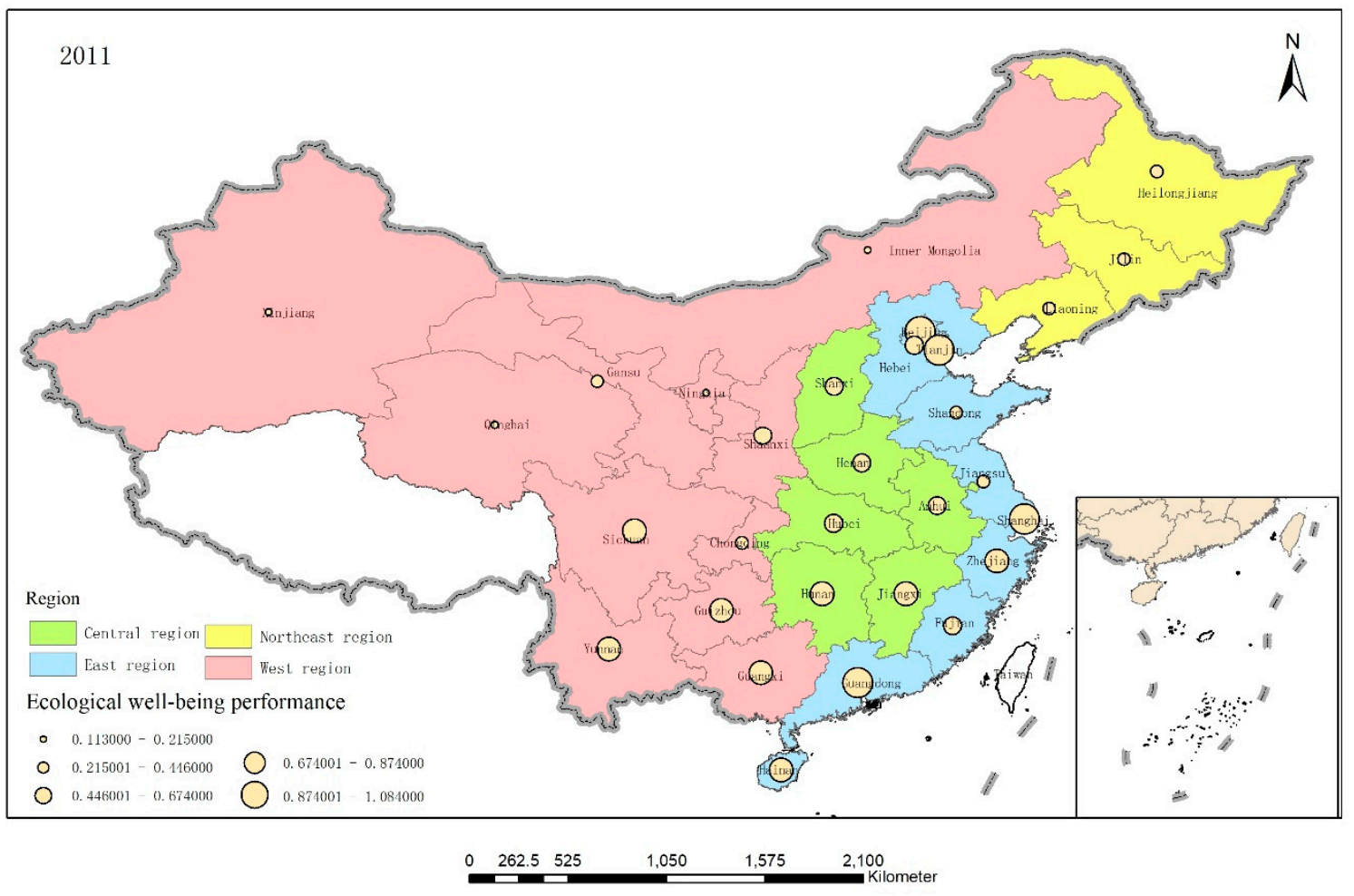

Figure 6. The EWP distributions in the 30 provinces in 2011.

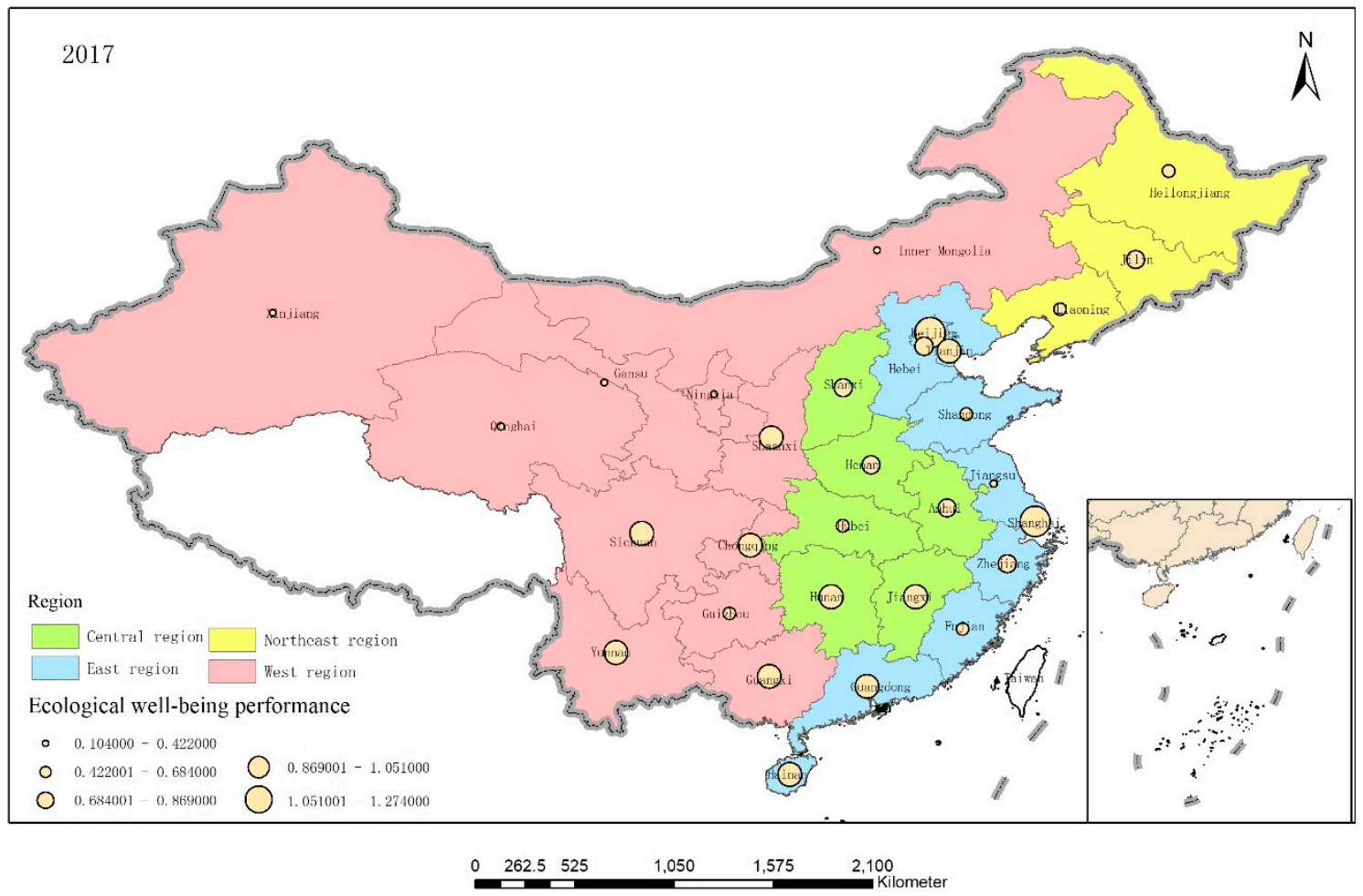

Figure 7. The EWP distributions in the 30 provinces in 2017.

Overall, although the average EWPs in the various regions descended from east to west, the spatial pattern was "high—low—high—low" as the western provinces were pushed to the forefront. China's EWP value appeared to be spatially supported by a quadrangular pole composed of Beijing, Shanghai, Hainan, and Sichuan and radiated to areas along these lines. However, the central and western regions 
appeared to form an economic development circle that had low resource utilization efficiency and high pollution while narrowing the economic gap.

\subsubsection{Spatial Correlation Analysis}

To explore the degree of EWP dependency between the 30 Chinese provinces, global and local spatial autocorrelation statistics measures were utilized [41]. First, the Moran's I statistic was applied, which is the most frequently used measurement for global spatial autocorrelation. The spatial weight matrix was constructed based on the first-order Rook method, after which the spatial correlation test of the EWP in the 30 provinces in China from 2006 to 2017 was conducted. The test results in Table 5 show that in the sample period, the Moran's I index was significant $(p<0.05)$ and the average value was greater than 0.2 , indicating that there was a positive spatial autocorrelation of the EWPs between the 30 provinces in China.

Table 5. Moran's I for China's Provincial EWP from 2006 to 2017.

\begin{tabular}{cccccc}
\hline Year & Moran's $\boldsymbol{I}$ & $\boldsymbol{p}$ & Year & Moran's $\boldsymbol{I}$ & $\boldsymbol{p}$ \\
\hline 2006 & 0.2707 & 0.0070 & 2012 & 0.3245 & 0.0050 \\
2007 & 0.2559 & 0.0060 & 2013 & 0.3086 & 0.0030 \\
2008 & 0.2764 & 0.0080 & 2014 & 0.3144 & 0.0050 \\
2009 & 0.1883 & 0.0340 & 2015 & 0.2545 & 0.0090 \\
2010 & 0.1736 & 0.0134 & 2016 & 0.2694 & 0.0100 \\
2011 & 0.2301 & 0.0170 & 2017 & 0.2427 & 0.0150 \\
\hline
\end{tabular}

Therefore, the EWPs in the 30 Chinese provinces had a certain agglomeration effect, which is the EWP in each province was affected by its own input-output and the EWP and industrial structures of the surrounding provinces. Moran's I statistic is a global statistic that provides greater insight into the local spatial associations between regions; therefore, to visualize the relationship between the regional observation value and its spatial lags, Moran's scatterplot, which measures the local spatial association, was derived with the EWP of each province on the horizontal axis and the EWP lag term of each province on the vertical axis. The weights were obtained from the spatial weighting matrix.

Figures 8-10 show the Moran's scatterplots for the Chinese provincial EWPs in 2006, 2011, and 2017, from which it can be seen that most provinces were located in quadrants $\mathrm{HH}$ (a province with a high EWP value surrounded by provinces of high values) and LL (a province with a low EWP value surrounded by provinces of low values), indicating that the spatial dependence of the EWP was superior to the spatial heterogeneity. The time trend also indicated that most provinces gradually converged to quadrants $\mathrm{HH}$ and LL and that the EWP spatial agglomeration effect in various provinces was increasingly prominent. This result was in line with the previous Moran's I statistics results that identified that the positive EWP spatial autocorrelation was significant between the Chinese provinces.

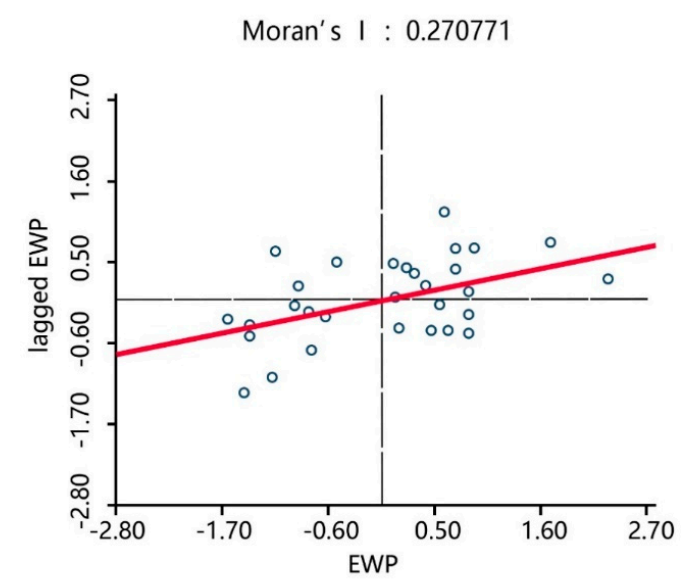

Figure 8. Moran's EWP scatterplots of the 30 provinces in 2006. 


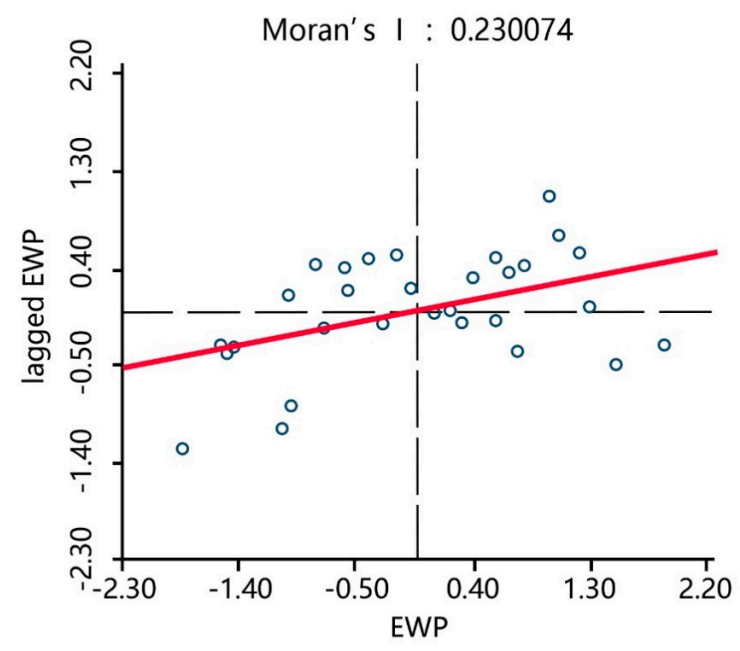

Figure 9. Moran's EWP scatterplots of the 30 provinces in 2011.

Moran's I : 0.242666

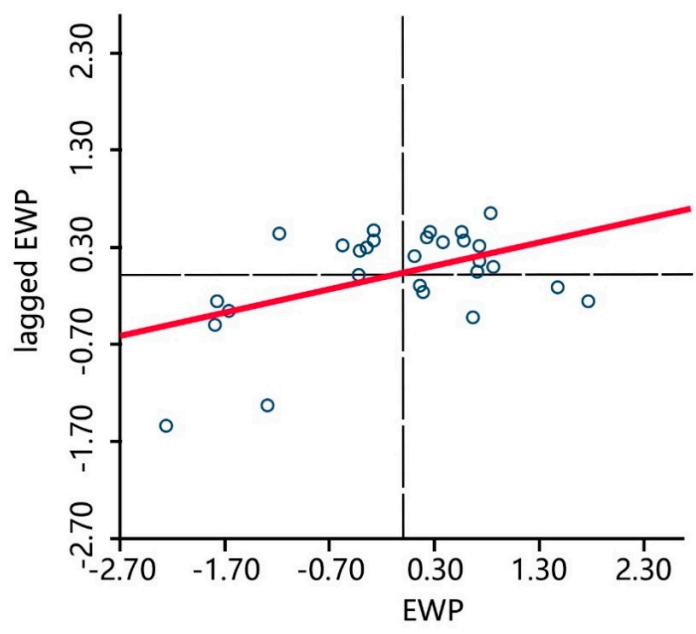

Figure 10. Moran's EWP scatterplots of the 30 provinces in 2017.

Therefore, the 30 Chinese provincial EWPs showed a gradient development trend with higher levels in the eastern coastal areas and lower levels in the western areas. As infrastructure construction such as highways and railways has developed, the free flow of element resources has strengthened the communication and cooperation between the regions, with the diffusion effect becoming more obvious over time, which has resulted in the EWPs in the different provinces having a certain spatial correlation with their adjacent regions.

\section{Conclusions}

To estimate regional sustainable development in China's provinces, it is important to examine their EWP levels. This study designed a comprehensive input-output, two-stage indicator system that concurrently assessed the desirable and undesirable outputs to examine provincial ecological wellbeing. A two-stage super-efficiency network SBM model and DEA analysis window method were employed to measure the EWP in 30 Chinese provinces from 2006 to 2017, from which the following were found.

(1) The average EWP in the 30 Chinese provinces was relatively low in the surveyed period, with the top three performers being Beijing, Hainan, and Shanghai and the poorest being Xinjiang, Ningxia, and Qinghai. While the average EW performances in S1 were slightly lower than in S2, neither were very high, with all 30 provinces failing to achieve concurrent DEA effectiveness in both stages. 
(2) Although the overall EWP across China was not high in the sample period, the average level fluctuated every year, but noticeably improved from 2011. Similar to the provincial trends, there was an obvious synchronous improvement in the average EWP in the four major Chinese regions, which indicated that the temporal EWP distribution in the 30 Chinese provinces had a basic "decline-rise-decline-rise" variation trend.

(3) There were significant geographically different features in the EWP in the regional provinces. The eastern Chinese provinces were ranked the highest, followed by the central, west, and northeast regions. The Chinese ecological wellbeing performances were found to be spatially supported by a quadrangular pole composed of Beijing, Shanghai, Hainan, and Sichuan and continued to radiate to areas along these lines. The spatial EWP agglomeration effect in the various provinces in China was more prominent when spatial correlation analysis methods were employed.

This paper makes three main contributions at least. First, although some works used province-level data to examine the EWP in China, most of their results focused on the single stage efficiency value, however our paper decomposed the EWP into the multiplication of EP and WP and further obtained two-stage super-efficiency performances. Second, some related capital indicators were innovatively introduced to reflect the ecological capital investment efficiency, which can be beneficial for comprehensively understating the provincial level EWP. Third, although some studies applied statistical methods to evaluate the EWP, their results were not considered from a spatial perspective. To overcome this limitation, we used spatial-temporal approaches to analyze and concluded the valuable spatial-temporal distribution rules. Even so, there were also some limitations. First, China's provincial regions need to be categorized based on their different levels to further enhance the generality of the findings regarding the spatial-temporal EWP differentiation. The ecological wellbeing performances of the individual provinces also need to be assessed as they have a duty to improve their EWP and experience sharing, organizational learning, and policy diffusion across cities can advance urban sustainable development. Besides, our results may be less accurate than city-level research because of ignoring the heterogeneity in each province; therefore, in the future, we can use individual city's data to depict more informative and reliable results. Second, the link between EWP and some factors in China's development should be studied to determine the EWP driving mechanisms and influence determinants, such as the relationships between industrial agglomeration, green technology development, and EWP.

Author Contributions: Conceptualization, J.H. and J.L.; methodology, X.R. and J.H.; software, X.R. and H.G.; writing —original draft preparation, J.H. and X.R.; writing—review and editing, J.H. and X.R.; funding acquisition, J.H. and H.G. All authors have read and agreed to the published version of the manuscript.

Funding: This research was funded by National Natural Science Foundation of China under grant number 71572185,71874163 , and 71874165 .

Conflicts of Interest: The authors declare no conflict of interest.

\section{References}

1. National Bureau of Statistics. National Bureau of Statistics of the People's Republic of China. Available online: http://www.stats.gov.cn/tjsj/zxfb/202002/t20200228_1728913.html (accessed on 28 February 2020).

2. Bian, J.; Zhang, Y.; Shuai, C.; Shen, L.; Ren, H.; Wang, Y. Have cities effectively improved ecological well-being performance? Empirical analysis of 278 Chinese cities. J. Clean. Prod. 2020, 245, 118913. [CrossRef]

3. Zhang, Y.; Chen, X.; Wu, Y.; Shuai, C.; Shen, L. The environmental Kuznets curve of $\mathrm{CO}_{2}$ emissions in the manufacturing and construction industries: A global empirical analysis. Environ. Impact Assess. Rev. 2019, 79, 106303. [CrossRef]

4. Gao, S.; Sun, H.; Cao, G.; Zhao, L.; Xu, M. Dynamic state of ecosystem carrying capacity under island urbanization: A case study of pingtan island in the southeastern coast of china. J. Environ. Eng. Landsc. Manag. 2020, 28, 1-8. [CrossRef] 
5. BP. BP Statistical Review of World Energy. Available online: https://www.bp.com/content/dam/bp/businesssites/en/global/corporate/pdfs/energy-economics/statistical-review/bp-stats-review-2020-full-report.pdf (accessed on 25 September 2020).

6. Li, H.; Yu, L. Chinese eco-city indictor construction. Urban Stud. 2011, 18, 81-86.

7. Huo, T.; Ren, H.; Cai, W. Estimating urban residential building-related energy consumption and energy intensity in China based on improved building stock turnover model. Sci. Total Environ. 2019, 650, 427-437. [CrossRef]

8. Bian, J.; Ren, H.; Liu, P. Evaluation of urban ecological well-being performance in China: A case study of 30 provincial capital cities. J. Clean. Prod. 2020, 254, 120109. [CrossRef]

9. Feng, Y.; Zhong, S.; Li, Q.; Zhao, X.; Dong, X. Ecological well-being performance growth in China (1994-2014): From perspectives of industrial structure green adjustment and green total factor productivity. J. Clean. Prod. 2019, 236, 117556. [CrossRef]

10. Daly, H.E. The world dynamics of economic growth: The economics of the steady state. Am. Econ. Rev. 1974, 64, 15-23.

11. Redclift, M. Sustainable development (1987-2005): An oxymoron comes of age. Sustain. Dev. 2005, 13, 212-227. [CrossRef]

12. Redclift, M. Sustainable development: Needs, values, rights. Environ. Values 1993, 2, 3-20. [CrossRef]

13. Beckerman, W. 'Sustainable development': Is it a useful concept? Environ. Values 1994, 3, 191-209. [CrossRef]

14. Rees, W.E. Ecological footprints and appropriated carrying capacity: What urban economics leaves out. Environ. Urban. 1992, 4, 121-130. [CrossRef]

15. Daly, H.E.; Cobb, J.B. For the Common Good: Redirecting the Economy toward Community, the Environment and a Sustainable Future; Beacon Press: Boston, MA, USA, 1989.

16. Veenhoven, R. World database of happiness. Soc. Indicat. Res. 1995, 34, 299-313. [CrossRef]

17. Sen, A. Capability and well-being. In The Quality of Life; Nussbaum, M., Sen, A., Eds.; Oxford Scholarship Press: Oxford, OH, USA, 1993; pp. 30-53.

18. Common, M. Measuring national economic performance without using prices. Ecol. Econ. 2007, 64, 92-102. [CrossRef]

19. Schneider, T.; Badii, R. The happy planet index 2.0: Why good lives don't have to cost the Earth. New Econ. Found. 2009, 18, L187-L193.

20. Dietz, T.; Rosa, E.A.; York, R. Environmentally efficient well-being: Is there a Kuznets curve? Appl. Geogr. 2012, 32, 21-28. [CrossRef]

21. Chen, P.; Xie, R.; Lu, M. “Resource conservation" or "environmental friendliness": How do urban clusters affect total-factor ecological performance in China? Int. J. Environ. Res. Public Health 2020, 17, 4361. [CrossRef] [PubMed]

22. Moran, D.D.; Wackernagel, M.; Kitzes, J.A.; Goldfinger, S.H.; Boutaud, A. Measuring sustainable development-nation by nation. Ecol. Econ. 2008, 64, 470-474. [CrossRef]

23. Dietz, T.; Rosa, E.A.; York, R. Environmentally efficient well-being: Rethinking sustainability as the relationship between human well-being and environmental impacts. Hum. Ecol. Rev. 2009, 16, 114-123.

24. Knight, K.; Rosa, E. The environmental efficiency of Well-being: Across national analysis. Soc. Sci. Res. 2011, 40, 931-949. [CrossRef]

25. Jorgenson, A.K.; Alekseyko, A.; Giedraitis, V. Energy consumption, human well-being and economic development in central and eastern European nations: A cautionary tale of sustainability. Energy Policy 2014, 66, 419-427. [CrossRef]

26. Zhu, D.; Zhang, S.; Sutton, D.B. Linking Daly's proposition to policymaking for sustainable development: Indicators and pathways. J. Clean. Prod. 2015, 102, 333-341. [CrossRef]

27. Zhang, S.; Zhu, D.; Shi, Q.; Cheng, M. Which countries are more ecologically efficient in improving human well-being? An application of the index of ecological well-being performance. Resour. Conserv. Recycl. 2018, 129, 112-119. [CrossRef]

28. Feng, J.; Yuan, J. On Chinese regional ecological well-being performance and its influence factors. Forum. Sci. Technol. China 2016, 3, 100-105.

29. Xu, Y.; Qi, P.; Tong, L. Spatial-temporal differentiation of Chinese provincial ecological well-being performance. Reg. Econ. Rev. 2017, 4, 123-131. 
30. Xiao, L.; Zhang, X. Spatio-temporal characteristics of coupling coordination between green innovation efficiency and ecological welfare performance under the concept of strong sustainability. J. Nat. Resour. 2019, 34, 312-324.

31. Fang, S.; Xiao, Q. Research on regional ecological well-being performance and spatial effect in China. China Popul. Resour. Environ. 2019, 29, 1-10.

32. He, L.; Chen, X. Study on sustainable economic development of Shaanxi province based on ecological well-being. Res. Dev. 2011, 6, 24-28.

33. Long, L.; Wang, X. A study on Shanghai's ecological well-being performance. China Popul. Resour. Environ. 2017, 27, 84-92.

34. Long, L. Evaluation of urban ecological well-being performance of Chinese major cities based on two-stage super-efficiency network SBM Model. China Popul. Resour. Environ. 2019, 29, 1-10.

35. Daly, H.E. Economics in a full world. Sci. Am. 2005, 293, 100-107. [CrossRef] [PubMed]

36. Zhu, D.; Qiu, S. Ecological efficiency is a suitable measure of circular economy. China Popul. Resour. Environ. 2016, 16, 1-6.

37. Yan, L.; Qu, Z.; Huang, L. Study on the efficiency of ecological capital in the perspective of economic green transformation. China Popul. Resour. Environ. 2013, 23, 18-23.

38. Bai, Y.; Deng, X.; Jiang, S.; Zhang, Q.; Wang, Z. Exploring the relationship between urbanization and urban eco-efficiency: Evidence from prefecture-level cities in China. J. Clean. Prod. 2018, 195, 1487-1496. [CrossRef]

39. Charnes, A.; Cooper, W.W.; Rhodes, E. Measuring the efficiency of decision making units. Eur. J. Oper. Res. 1978, 2, 429-444. [CrossRef]

40. Li, Z.; Ouyang, X.; Du, K.; Zhao, Y. Does government transparency contribute to improved eco-efficiency performance? An empirical study of 262 cities in China. Energy Policy 2017, 110, 79-89. [CrossRef]

41. Hou, J.; Lv, J.; Chen, X.; Yu, S. China's regional social vulnerability to geological disasters: Evaluation and spatial characteristics analysis. Nat. Hazards 2016, 84, 97-111. [CrossRef]

42. Hu, Z.; Zhao, Z.; Zhang, Y.; Jing, H.; Gao, S.; Fang, J. Does 'Forage-Livestock Balance' policy impact ecological efficiency of grasslands in China? J. Clean. Prod. 2019, 207, 343-349. [CrossRef]

43. Tone, K. A slacks-based measure of efficiency in data envelopment analysis. Eur. J. Oper. Res. 2001, 130, 498-509. [CrossRef]

44. Tone, K.; Tsutsui, M. Dynamic DEA: A slacks-based measure approach. Omega 2010, 38, 145-156. [CrossRef]

45. Dewarlo, O. DEA window analysis for measuring port performances efficiency of four islands countries located in west Indian ocean countries. Am. J. Ind. Busi. Manag. 2019, 9, 2098-2111. [CrossRef]

46. Charnes, A.; Clark, C.T.; Cooper, W.W.; Golany, B. A developmental study of data envelopment analysis in measuring the efficiency of maintenance units in the U.S. air forces. Ann. Oper. Res. 1984, 2, 95-112. [CrossRef]

47. SCPRC. Implementation Opinions on Promoting Ecological Protection and Green Development of Ecological Conservation Areas. Available online: http://www.gov.cn/xinwen/2018-11/06/content_5337816.htm (accessed on 11 March 2020).

48. National Bureau of Statistics. Yearbook of National Bureau of Statistics; China Statistics Press: Beijing, China, 2011.

(C) 2020 by the authors. Licensee MDPI, Basel, Switzerland. This article is an open access article distributed under the terms and conditions of the Creative Commons Attribution (CC BY) license (http://creativecommons.org/licenses/by/4.0/). 